\title{
Cloning, Sequencing and In Silico Analysis of Omp C of Salmonella Typhimurium
}

\author{
Richa Jha, ${ }^{1}$ Anil Kumar, ${ }^{1}$ Anjani Saxena, ${ }^{2}$ Shantanu Tamuly, ${ }^{2}$ and M. K. Saxena ${ }^{2}$ \\ ${ }^{1}$ Department of Molecular Biology and Genetic Engineering, G.B. Pant University of Agriculture \& Technology, \\ Pantnagar 263145, India \\ ${ }^{2}$ Animal Biotechnology Center, Department of Veterinary Physiology \& Biochemistry, \\ G.B. Pant University of Agriculture \& Technology, Pantnagar 263145, India
}

Correspondence should be addressed to M. K. Saxena, mumtesh@rediffmail.com

Received 22 November 2011; Accepted 26 December 2011

Academic Editor: H. Akashi

Copyright (๑) 2012 Richa Jha et al. This is an open access article distributed under the Creative Commons Attribution License, which permits unrestricted use, distribution, and reproduction in any medium, provided the original work is properly cited.

Salmonella Typhimurium is an important pathogen having a broad host range. In human population it causes mostly gastroenteritis but there are reports in which it was found to be responsible to cause several lethal diseases like endocarditis and meningitis. Poultry products are the major sources of this organism in India as these are consumed at various stages of cooking. The available vaccines have their own limitations such as short-term immunity. Outer membrane proteins have shown some promising potential, so in the present study Omp C of Salmonella Typhimurium was cloned and sequenced to explore the possibility of development of r-DNA vaccine against Salmonella Typhimurium for poultry. The sequence of Omp C was studied for antigenic indexing, epitope mapping, and MHC mapping using various bioinformatic tools. The ORF analysis revealed a complete coding region of approximately $1000 \mathrm{bp}$. Five major and 13 minor B-cell epitopes were identified having an antigenic index of 1.7. The sequences also showed major histocompatibility complex (MHC) class I and class II binding region indicating a potential of eliciting cell-mediated immune response. The findings indicate that Omp C may be proven as promising candidate for development of r-DNA vaccine against Salmonella Typhimurium.

\section{Introduction}

Salmonellosis is a major foodborne illness and life-threatening problem worldwide caused by various serovars of Salmonella among which Salmonella Typhimurium is one of the most important serovars. In developing countries like India where the hygienic conditions are not very good salmonelloses have became major problem related to human health and poultry products are known to be significant reservoir for Salmonella and most important source to human infections $[1,2]$. The available vaccines for poultry in India are not very effective $[3,4]$. The backyard poultry practices are very common in India so there is always a possibility of transfering of Salmonella Typhimurium from poultry to human populations where it can cause serious health problems $[5,6]$. There is an emergent need of better vaccine for poultry against salmonellosis.

In last few years Omps have been studied and have shown their immunopotential [7-9]. Few of them have been characterized [10]. In earlier report Omp C has been studied [11], and it was found that Omp C was expressed during high salt concentration which was equivalent to human serum [12]. It was found be thermostable [13] and resistant for proteolysis [14]. This finding indicates that Omp C may be proven as an efficient candidate for vaccine development. As the isolation of individual Omp in large scale for development of an effective vaccine is a labour intensive and costly procedure, the present study deals with the cloning, sequencing, and in silico analysis of Omp C gene of Salmonella Typhimurium to explore the possibility of development of r-DNA vaccine against poultry salmonellosis.

\section{Materials and Methods}

2.1. Bacterial Strains. Culture of Salmonella Typhimurium (MTCC 3231) was procured from Institute of Microbial Technology, Chandigarh, India and maintained in Luria Bertini media. Escherichia coli DH5 $\alpha$ used in cloning experiment 


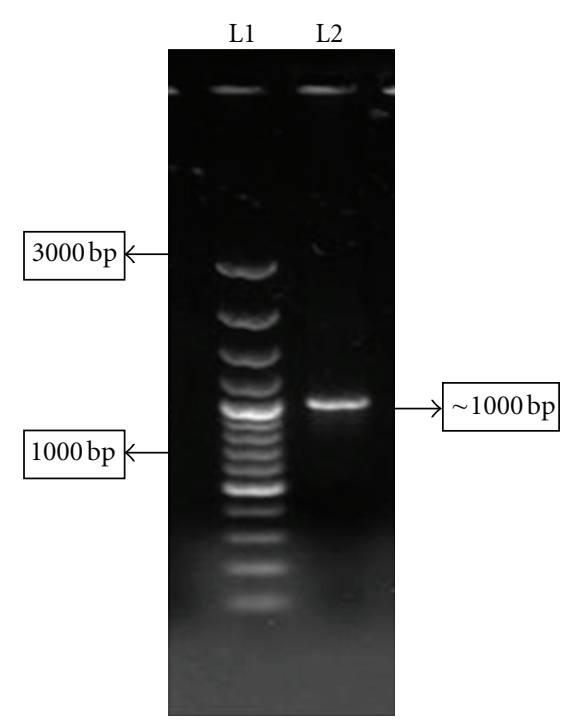

Figure 1: L1: GeneRuler 100 bp Plus DNA Ladder (MBI Fermentas). L2: PCR Product ( $1000 \mathrm{bp})$.

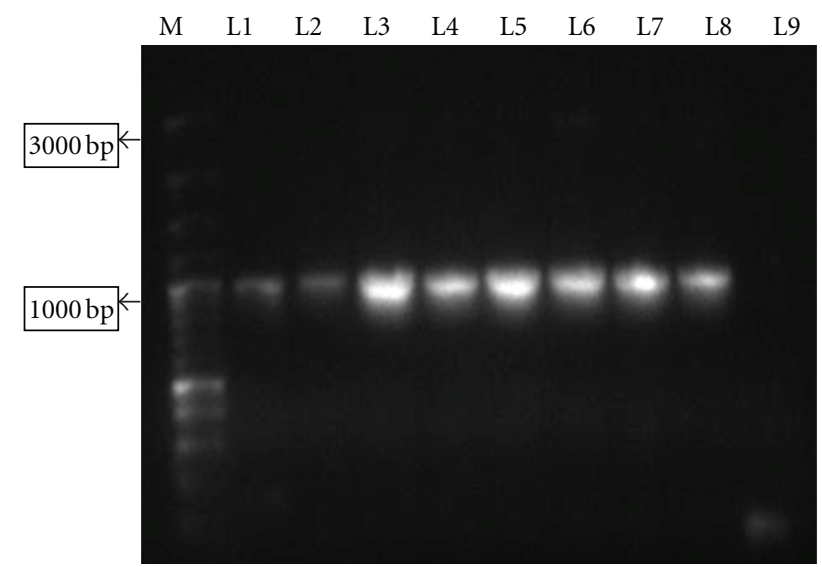

Figure 2: M: GeneRuler 100 bp Plus DNA Ladder (MBI Fermentas), L1-L8: PCR products of cloned plasmids, L9: negative control.

was purchased from Bangalore Genei, India and grown in LB broth.

Blunt cloning vector pJET 1.2, blunting enzyme, and T4 DNA ligase were procured from Qiagen, USA. The antibiotics (Ampicillin $(100 \mu \mathrm{g} / \mathrm{mL})$ and Kanamycin $(50 \mu \mathrm{g} / \mathrm{mL})$ ) used for selection of recombinants were procured from $\mathrm{Hi}$ media, India.

The cultures were maintained in LB agar slants and their purity was tested by biochemical tests and Salmonella specific PCR.

2.2. Cloning of Omp C Gene. Genomic DNA was isolated by CTAB method [14]. Primers were designed for Omp C gene of Salmonella Typhimurium using sequence information available on NCBI and using gene tool software.

Forward primer-5' GGATCCATGCGTATCGGCTT3'.

Reverse primer-5'AAGCTTTTAGAACTGGTAAA3'.

$25 \mu \mathrm{L}$ PCR reaction mixture containing $40 \mathrm{ng}$ of genomic DNA, 20 pmole of primers, $200 \mu \mathrm{M}$ of each dNTPs, $1.5 \mathrm{Mm}$

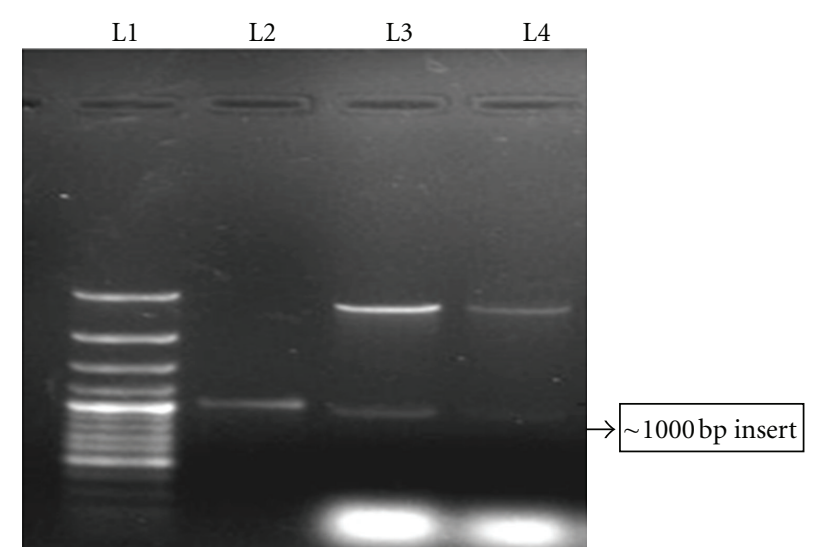

Figure 3: Release of insert through restriction digestion. L1: GeneRuler 100 bp Plus DNA Ladder (MBI-Fermentas), L2: eluted PCR product, L3-4: insert release form cloned recombinant plasmid.

$\mathrm{MgCl}_{2}$ and $2 \mathrm{U}$ of jumpstart polymerase (Sigma, USA). The gene was amplified by PCR using the following programme, that is, initial denaturation at $94^{\circ} \mathrm{C}$, followed by 30 cycles of denaturation at $94^{\circ} \mathrm{C}$, annealing at $46^{\circ} \mathrm{C}$, and elongation at $72^{\circ} \mathrm{C}$. All the reagents used for PCR except enzyme were procured from Bangalore Genei, India. The amplified product was checked on $1 \%$ agarose gel and elution of the purified product was carried out using QIA quick gel extraction kit (Qiagen, USA). Blunting was carried out using standard kit procedures (pJET cloning kit, Qiagen, USA) and the product was cloned into pJET cloning vector through blunt end ligation. The ligate was transformed in chemically induced competent $E$. coli DH5 $\alpha$ cells. Clones were inoculated in LB ampicillin tubes and plasmid was isolated by the alkaline lysis method and insert from plasmid was released by digestion with Bam HI and Hind III restriction enzymes.

The recombinant clones were screened to obtain insert of desired size verified by colony PCR amplification. The cloned product was sequenced by Ocimum Biosolutions Ltd., Hyderabad. The sequence was submitted to NCBI.

2.3. Sequence Similarity and Phylogenetic Analysis. The sequence obtained was subjected to homology search using BLASTn (http://www.ncbi.nlm.nih.gov/). The sequence showing maximum similarity with Omp C was subjected to multiple sequence alignment by CLUSTALW and a phylogenetic tree was constructed, based on the comparative analysis of related protein sequences, using UPGMA method.

Amino acids sequence was translated using DNASTAR Inc, USA, software. Structural analysis of Omp C was carried out using different online servers, namely, Protparam (EXPA-syserver: Protparam) [7], Pfam (http://pfam.sanger .ac.uk/), and PDB server (http://www.ebi.ac.uk/pdbsum/).

\section{Results and Discussion}

The purity of the culture was checked by biochemical characterization and Salmonella-specific PCR. The culture was 


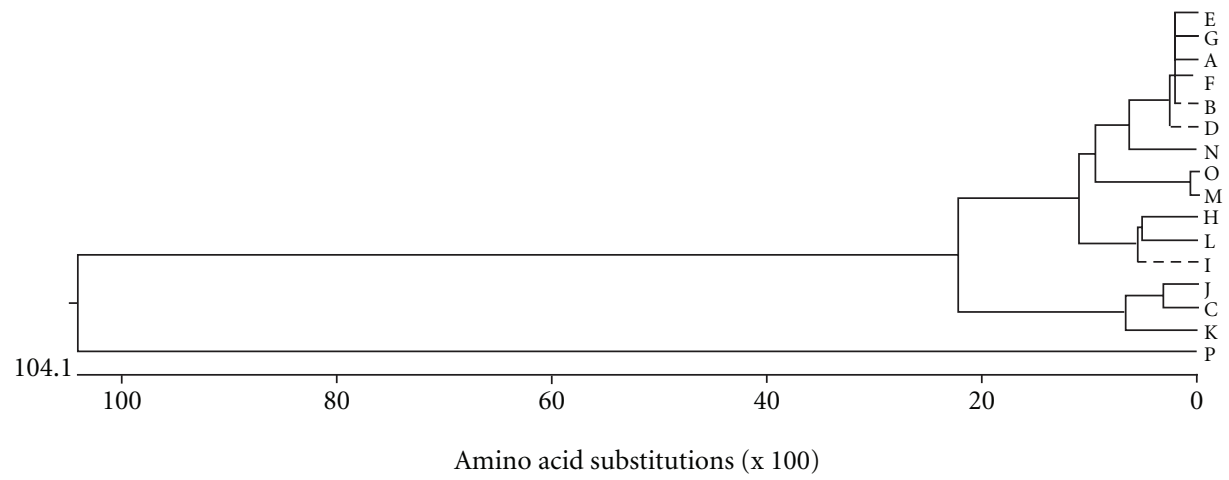

Figure 4: Phylogenetic tree of amino acid sequences of related sequences. A. Outer membrane protein N precursor [Salmonella enterica subsp. enterica serovar Wandsworth str. A4-580]. B. Hypothetical protein SPAB_01846 [Salmonella enterica subsp. enterica serovar Paratyphi B str. SPB7]. C. Porin, Gram-negative type [Salmonella enterica subsp. enterica serovar Dublin str. SD3246]. D. Outer membrane protein N [Salmonella enterica subsp. enterica serovar Heidelberg str. SL486]. E. Outer membrane protein N [Salmonella enterica subsp. enterica serovar Newport str. SL254]. F. Outer membrane protein [Salmonella enterica subsp. enterica serovar Gallinarum str. RKS5078]. G. Outer membrane protein N [Salmonella enterica subsp. enterica serovar Dublin str. CT_02021853]. H. Outer membrane protein [Salmonella enterica subsp. enterica serovar Montevideo str. LQC 10]. I. Outer membrane protein N precursor [Salmonella enterica subsp. enterica serovar Urbana str. R8-2977]. J. Outer membrane protein N precursor [Salmonella enterica subsp. enterica serovar Hvittingfoss str. A4-620]. K. Outer membrane protein N precursor [Salmonella enterica subsp. enterica serovar Mississippi str. A4-633]. L. Outer membrane protein N [Salmonella enterica subsp. enterica serovar Saintpaul str. SARA29]. M. Hypothetical protein STY1649 [Salmonella enterica subsp. enterica serovar Typhi str. CT18]. N. Outer membrane protein N [Salmonella enterica subsp. enterica serovar Javiana str. GA_MM04042433]. O. Outer membrane protein [Salmonella enterica subsp. enterica serovar Typhi str. E00-7866]. P. outer membrane protein C [Salmonella enterica subsp. enterica serovar Typhimurium].

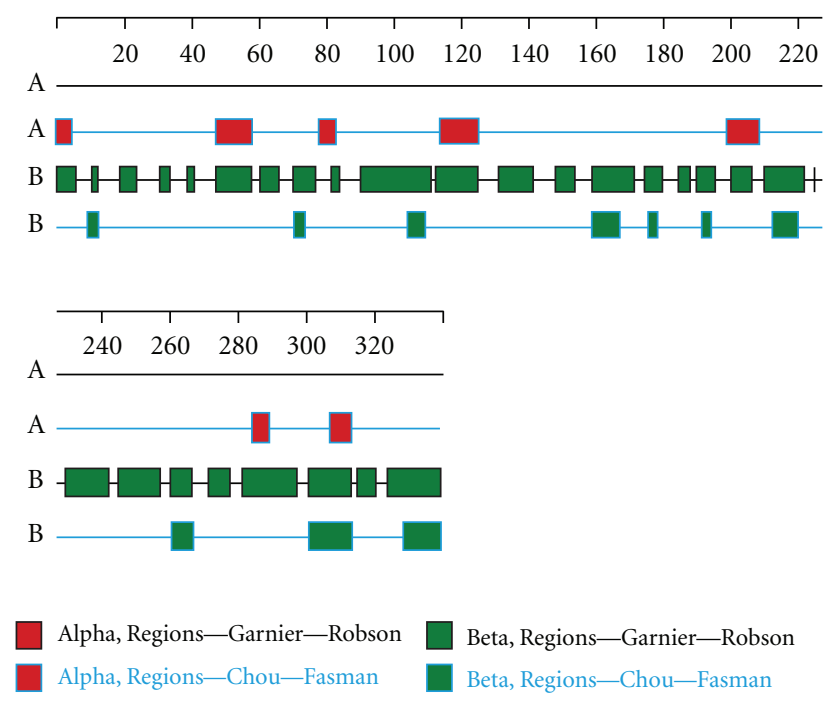

FIgURE 5: Structural analysis by DNASTAR software.

found to be MR+, VP-, Urease- biochemically, which is characteristic of Salmonella Typhimurium. In PCR amplification an amplicon of 496 bp was obtained which confirmed the identification through biochemical tests.

3.1. PCR Amplification and Cloning. The PCR amplification with Omp-C-specific primers was conducted with genomic DNA, which resulted in a product of approximate size $1000 \mathrm{bp}$ (Figure 1). The desired product was successfully purified using QIA quick gel extraction kit and cloned in pJET 1.2 blunt cloning vector (Fermentas, USA) and transformed into chemically competent E.coli DH5 $\alpha$ cells.
Recombinant clones were selected by colony PCR (Figure 2). Restriction digestion of isolated recombinant plasmids was found to release an insert of $\sim 1000 \mathrm{bp}$ of Omp $\mathrm{C}$ gene (Figure 3 ). The insert was sequenced and complete cds was submitted in NCBI Genbank and assigned the Accession no. JF896322. The amplified product was found to be $\sim 1 \mathrm{~kb}$ and the complete cds was of $993 \mathrm{bp}$ having a GC content of $47.53 \%$.

3.2. Sequence Analysis of S. Typhimurium Omp C Gene. The NCBI BLAST search of the Omp C gene showed maximum homology (99\%) with outer membrane proteins of serovars 

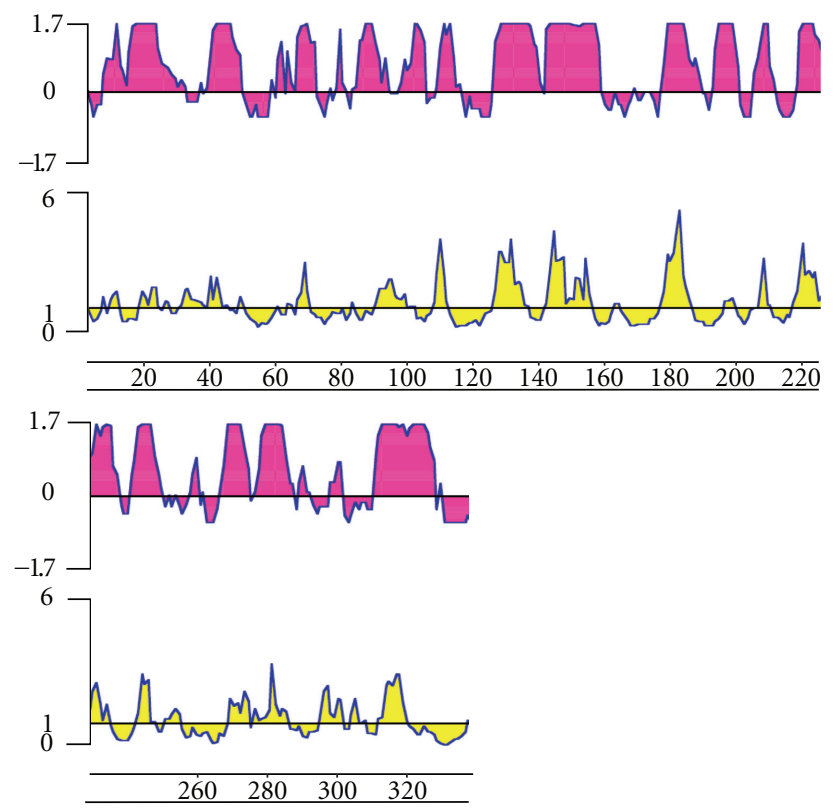

Antigenic Index-Jameson-Wolf

Surface Probability Plot-Emini

Figure 6: Antigenic index and Surface Probability plot of translated Omp C gene sequence.

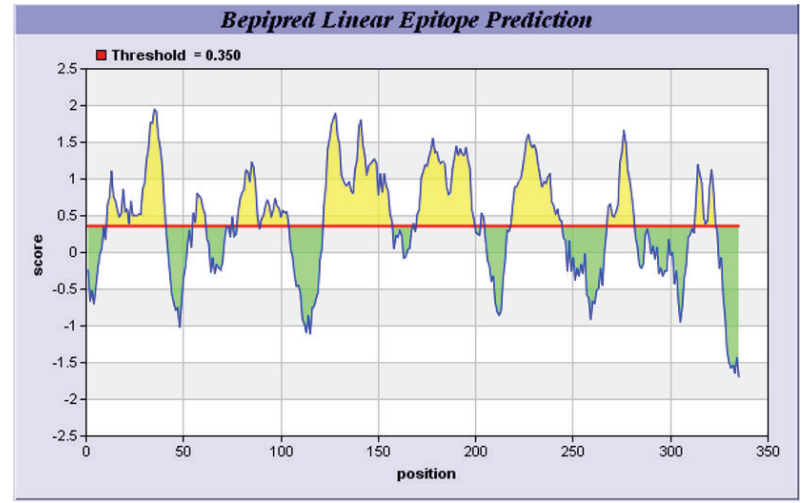

Average:0.412 Minimum:-1.705 Maximum:1.951 Threshold: 0.350 Change

FIGURE 7: B-cell epitope prediction through IEDB online epitope prediction tool.

like S. enterica serovar Typhi, Gallinarum, and Paratyphi. Multiple sequence alignment showed that it is closely related to Omp C of S. Typhi. The sequence shows 75\% similarity with E. coli Omp C (Figure 4).

By bioinformatic analysis using DNA STAR software, the protein was found to have 330 amino acids. 24 amino acids were strongly basic $(+)(K, R), 45$ strongly acidic $(-)(D, E)$, 95 hydrophobic (A, I, L, F, W, V), and 112 polar amino acids (N, C, Q, S, T, Y). It shows an isoelectric point at $\mathrm{pH} 4.02$. At physiological $\mathrm{pH}$ the protein has a net negative charge $(-21.08)$.

PSORTb v 3.0 analysis revealed the presence of noncytoplasmic signal peptide in the protein which indicated the subcellular localization of the protein. The location of the protein depends on the presence of signal peptide and membrane spanning alpha helixes. We found six major alpha helical regions throughout the protein by secondary structure analysis. There were more beta regions then alpha regions in Omp C gene (Figure 5).

Prosite analysis showed the presence of five motifs in Omp C gene, that is, protein kinase $\mathrm{C}$ phosphorylation site at four locations (10-12, 99-101, 107-109, 180-182), Nglycosylation site at four locations (38-41, 130-133, 241244, 299-302), casein kinase II phosphorylation site at seven locations (40-43, 92-95, 134-137, 163-166, 178-181, 302305, 324-327), N-myristoylation site at three locations (55$60,168-173,237-242$ ), and tyrosine kinase phosphorylation site at two locations (145-153, 268-274).

Pfam analysis showed the protein to be a member of gram-negative porin family. Blastp was performed by Swissprot model analysis. This showed maximum similarity with Omp N of Salmonella enterica subsp. enterica serovars (99\%). The protein sequence was also found to be $98 \%$ similar to outer membrane protein S2 of Salmonella Typhi and $96 \%$ to outer membrane protein $\mathrm{N}$ of S. paratyphi and $S$. arizonae.

Antigenic characterization of the translated protein sequence was done by protean [15]. The surface probability plot represented several hydrophilic exposed domains in the Omp C protein sequence. These exposed regions comprised the major epitopes of the protein, some of them being unique. The antigenic index collaborated with the hydrophilic regions and creates a linear surface contour profile of the protein. Antigenic sites were found to be located within 
TABLE 1: Major B-cell epitopes.

\begin{tabular}{lcccc}
\hline No. & Start Position & End Position & Peptide & Peptide length \\
\hline 1 & 11 & 40 & ETQINDQLTGYGQWEYNVQANTTEGEGANS & GSFDYGR \\
2 & 55 & 61 & WT & 7 \\
3 & 72 & 73 & M & 2 \\
4 & 75 & 75 & EFGGDSYTYAD & 1 \\
5 & 78 & 88 & YMTGRANGVATYRNT & 11 \\
6 & 90 & 104 & KNESQSADDVNIGTNNRNNGDDIRYDNGDGFGISTT & 36 \\
7 & 122 & 168 & A & 1 \\
8 & 168 & 199 & YTTSDRTNEQVNAGGTIAGGDKADAWTAGL & 30 \\
9 & 170 & 204 & AN & 2 \\
10 & 203 & 244 & MTPYGKTDAGYAGGVANKTQNFEVTAQ & 14 \\
11 & 218 & 281 & NNVNGDDKDLVKYA & 11 \\
12 & 268 & 323 & DAGISTDDIVA & \\
13 & 313 & &
\end{tabular}

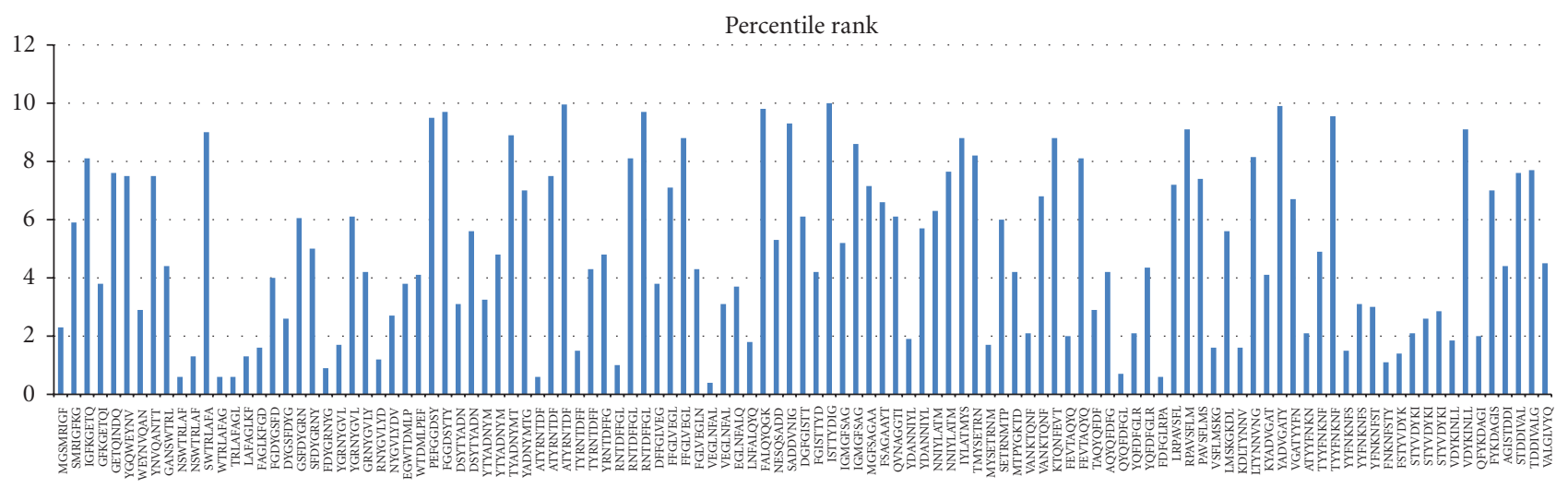

FIgURE 8: MHC I epitopes identified through IEDB epitope prediction tool.

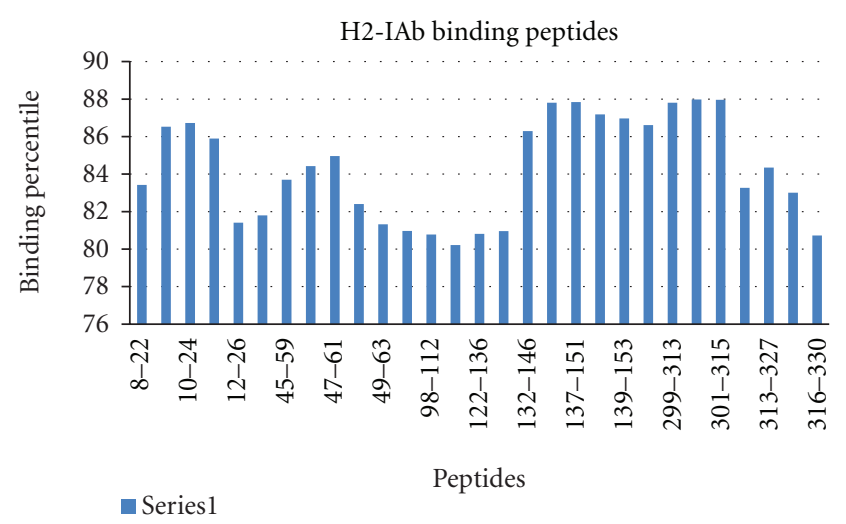

FIgURE 9: H2-IAb epitope prediction thorough IEDB.

the surface-exposed regions of the protein. Protean predicted five major epitopes, two of them occupying the 130-160 amino acid region and having maximum surface probability [16]. Approximately 13 minor epitopes were observed in the analysis. The epitopes have the maximum antigenic index of 1.7 (Figure 6).

3.2.1. B-Cell Epitope Prediction. To find out the B-cell epitope regions of Omp protein the BepiPred prediction tool of
IEDB analysis resources was used. The sequence was loaded into the tool window and searched for most potential linear epitopes (Figure 7).

Total of 13 B cell epitopes were analyzed (Table 1). Among these 13 epitopes mainly eight were found to be more immunogenic as predicted by the scores of epitope. A peptide length of 10 or more amino acid are supposed to be good B cell epitope.

3.2.2. T-Cell Epitope Prediction. A critical step in developing immune response against pathogens is the recognition of antigenic peptides presented by MHC class I and II molecules. Peptides are divided into binders and nonbinders and binding affinities of MHC class I and II are calculated by epitope database analysis and ranked according to their percentile. Total 14 MHC I epitopes were found in the analysis including 5 high affinity epitopes (Figure 8).

For MHC class II a percentile rank for each of the four methods (ARB, Combinatorial library SMM-align and Sturniolo) was generated by comparing the peptide score against the scores of five million 15 mers selected from SWISS-PROT database. A small percentile rank indicates high affinity. A graph was been plotted between percentile rank and amino acid position. There are three types of MHC class II reported in case of mice for example, H2 IAB, H2 IAD, H2 IED. 


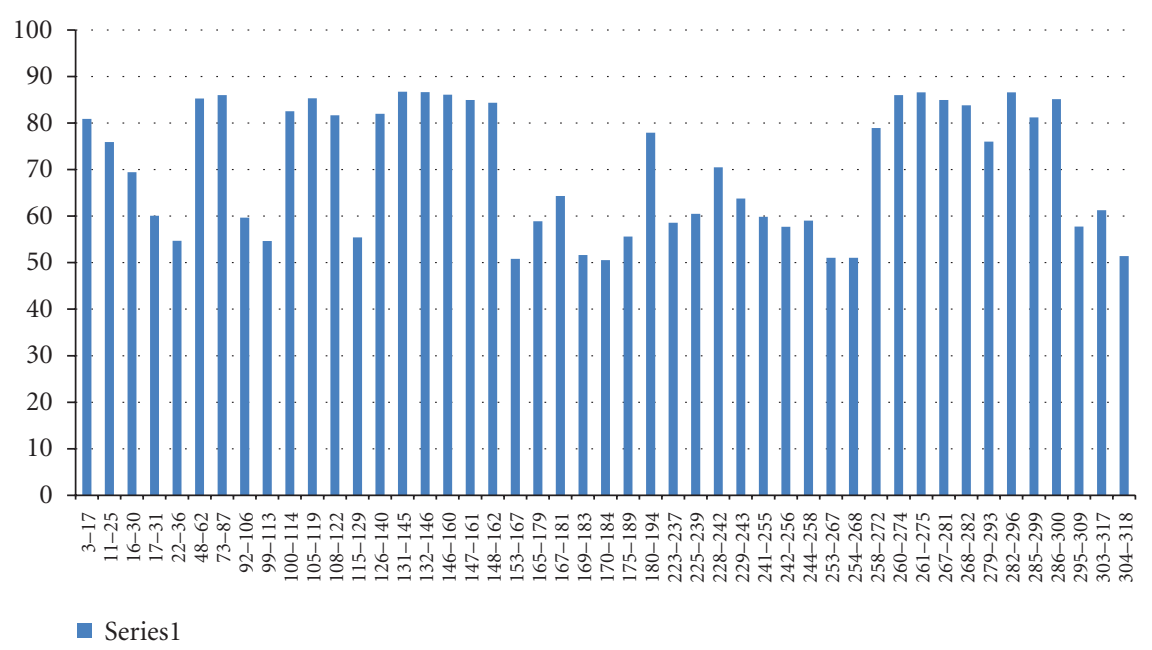

FIgURE 10: H2-IAd epitope prediction thorough IEDB.

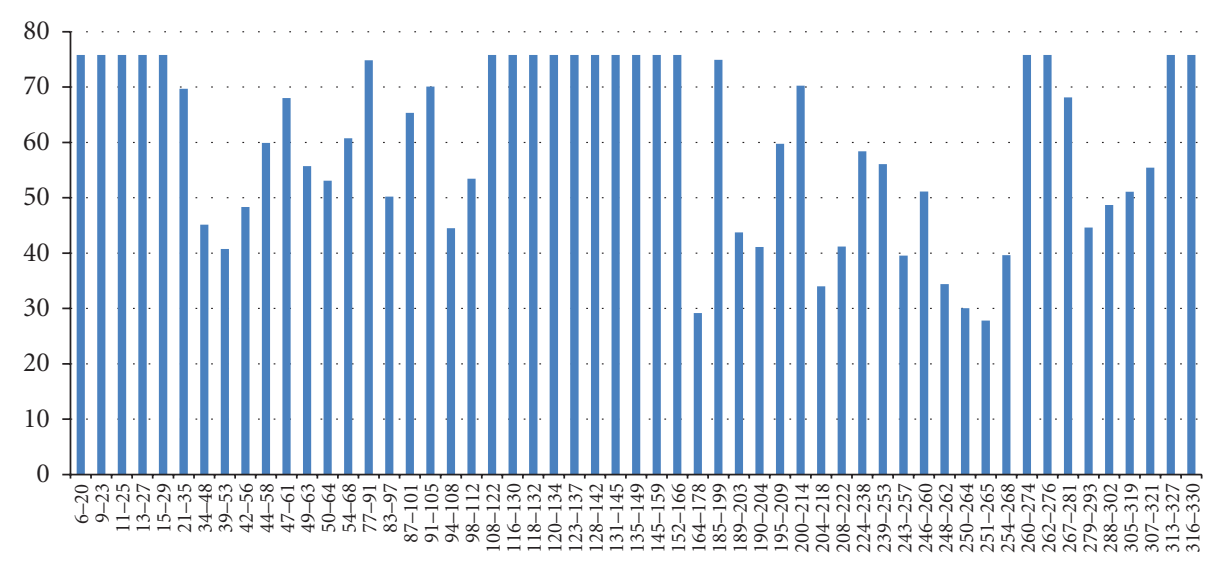

- Series1

FIGURE 11: H2-IEd epitope prediction thorough IEDB.

Data has been analyzed by bar diagram against amino acid position and median percentile rank.

In case of H2-IAb 12 high-affinity MHCII binding sites were found. In H2-IAd, 23 high-affinity MHCII binding sites were observed and in H2-IEd, and 19 high binding sites were found (Figures 9, 10, and 11).

It has been reported through multiple sequence alignment tools that $S$. Typhi Omp C consists of 8 variable regions on comparison with other porins with well-known crystal structures [17]. These variable regions have been found to be on the outer side of the membrane and therefore they have high probability to be presented for B-cell recognition and elicit immune response. These findings clearly depict that Omp C has recognized B-cell epitopes and as it shares maximum similarity with Omp C of S. Typhimurium (98\%) these variable regions can be strongly predicted to act as possible B-cell epitopes capable of eliciting immune response.

Sequencing revealed that the C-terminus of Omp C has typical characteristic of Omps. The last residue at the $\mathrm{C}$ terminus, phenylalanine, has been reported to be highly conserved among outer membrane proteins and is essential for stability and correct assembly of protein into the outer membrane [18]. The $15 \mathrm{C}$ terminal amino acid residues of Omp C including the terminal phenylalanine were found to be hydrophobic in nature which is important for incorporation of the protein in the membrane.

Omp C of Salmonella has been purified using salt extraction procedures [19], and its epitopes have been mapped [20]. It is found to be a trimer made of 16 stranded $\beta$ barrel monomers and is a major cell surface antigen from the human pathogen Salmonella typhi. The assembly of trimer and the stability of the $\beta$-barrel have been found to be important for epitope presentation. The Salmonella-specific conformational epitope was found to be more stable than in case of Enterobacteria [20].

It is a good candidate to display heterologous epitopes on the cell surface $[21,22]$. The functional and mature Omp C is a homotrimer. The monomer without the signal peptide has 357 amino acids and a molecular weight of $39 \mathrm{kDa}$. The purification and crystallization of native Ty21a Omp C 
have been described earlier [19]. Omp C is expressed not only under free living conditions, but also during infection, since the osmolarity of the human serum is equivalent to high salt conditions maintained in the laboratory [23]. These reasons suggest that $\mathrm{Omp} \mathrm{C}$ could be a candidate antigen for diagnostics and vaccination. Omp C was found to be conserved within eleven Salmonella serotypes [11]. These findings indicate that Omp C can be in further studies for vaccine development against a range of serovars and its epitope mapping reveals its high immunogenic potential as an r-DNA vaccine candidate.

\section{References}

[1] A. Maripandi and A. A. Al-Salamah, "Multiple-antibiotic resistance and plasmid profiles of Salmonella enteritidis isolated from retail chicken meats," American Journal of Food Technology, vol. 5, no. 4, pp. 260-268, 2010.

[2] P. N. Acha and B. Szyfres, Zoonoses and Communicable Diseases Common to Man and Animal: Bacterioses and Mycoses, Pan American Health Organization, 3rd edition, 2001.

[3] E. K. Barbour, W. M. Frerichs, N. H. Nabbut, P. E. Poss, and M. K. Brinton, "Evaluation of bacterins containing three predominant phage types of Salmonella enteritidis for prevention of infection in egg-laying chickens," American Journal of Veterinary Research, vol. 54, no. 8, pp. 1306-1309, 1993.

[4] R. K. Gast, H. D. Stone, and P. S. Holt, "Evaluation of the efficacy of oil-emulsion bacterins for reducing fecal shedding of Salmonella enteritidis by laying hens," Avian Diseases, vol. 37, no. 4, pp. 1085-1091, 1993.

[5] G. Moreno, C. Moar, F. Roman, M. R. Perez, D. Lopez, and J. M. Letona, "Salmonella endocarditis presenting as cerebral hemorrhagez," European Journal of Internal Medicine, vol. 11, pp. 96-97, 2000.

[6] K. Swe, G. Nage, M. Van Der Westhuizen, and A. A. Hoosen, "Salmonella typhimurium meningitis in an adult patient with AIDS," Journal of Clinical Pathology, vol. 61, no. 1, pp. 138139, 2008.

[7] A. Isibasi, V. Ortiz, M. Vargas et al., "Protection against Salmonella typhi infection in mice after immunization with outer membrane proteins isolated from Salmonella typhi," Infection and Immunity, vol. 56, no. 11, pp. 2953-2959, 1988.

[8] J. Luis Puente, V. Alvarez-Scherer, G. Gosset, and E. Calva, "Comparative analysis of the Salmonella typhi and Escherichia coli ompC genes," Gene, vol. 83, no. 2, pp. 197-206, 1989.

[9] N. Hamid and S. K. Jain, "Characterization of an outer membrane protein of Salmonella enterica serovar Typhimurium that confers protection against typhoid," Clinical and Vaccine Immunology, vol. 15, no. 9, pp. 1461-1471, 2008.

[10] J. Lin, S. Huang, and Q. Zhang, "Outer membrane proteins: key players for bacterial adaptation in host niches," Microbes and Infection, vol. 4, no. 3, pp. 325-331, 2002.

[11] J. L. Puente, D. Juárez, M. Bobadilla, C. F. Arias, and E. Calva, "The Salmonella ompC gene: structure and use as a carrier for heterologous sequences," Gene, vol. 156, no. 1, pp. 1-9, 1995.

[12] J. L. Puente, A. Verdugo-Rodriguez, and E. Calva, "Expression of Salmonella typhi and Escherichia coli OmpC is influenced differently by medium osmolarity; dependence on Escherichia coli OmpR," Molecular Microbiology, vol. 5, no. 5, pp. 12051210, 1991.

[13] N. S. Baalaji, M. K. Mathew, and S. Krishnaswamy, "Functional assay of Salmonella typhi OmpC using reconstituted large unilamellar vesicles: a general method for characterization of outer membrane proteins," Biochimie, vol. 88, no. 10, pp. 1419-1424, 2006.

[14] A. Arockiasamy, P. D. Kumar, N. S. Baalaji, M. R. Rukmini, and S. Krishnaswamy, "Folding and structural stability of OmpC from Salmonella typhi: role of LPS and environment," Current Science, vol. 87, no. 2, pp. 197-202, 2004.

[15] T. N. Plasterer, "PROTEAN: protein sequence analysis and prediction," Methods in Molecular Biology, vol. 70, pp. 227239, 1997.

[16] B. A. Jameson and H. Wolf, "The antigenic index: a novel algorithm for predicting antigenic determinants," Computer Applications in the Biosciences, vol. 4, no. 1, pp. 181-186, 1998.

[17] A. Arockiasamy and S. Krishnaswamy, "Prediction of B-cell epitopes for Salmonella typhi OmpC," Journal of Biosciences, vol. 20, no. 2, pp. 235-243, 1995.

[18] C. G. Ruffolo and B. Adler, "Cloning, sequencing, expression, and protective capacity of the oma87 gene encoding the $P$. multocida 87-kilodalton outer membrane antigen," Infection and Immunity, vol. 64, no. 8, pp. 3161-3167, 1996.

[19] A. Arockiasamy and S. Krishnaswamy, "Purification of integral outer-membrane protein OmpC, a surface antigen from Salmonella typhi for structure-function studies: a method applicable to enterobacterial major outer-membrane protein," Analytical Biochemistry, vol. 283, no. 1, pp. 64-70, 2000.

[20] A. Arockiasamy, G. S. Murthy, M. R. Rukmini, N. Sundara Baalaji, U. C. Katpally, and S. Krishnaswamy, "Conformational epitope mapping of $\mathrm{OmpC}$, a major cell surface antigen from Salmonella typhi," Journal of Structural Biology, vol. 148, no. 1, pp. 22-33, 2004.

[21] A. Arockiasamy and S. Krishnaswamy, "Homology model of surface antigen OmpC from Salmonella typhi and its functional implications," Journal of Biomolecular Structure and Dynamics, vol. 18, no. 2, pp. 261-271, 2000.

[22] J. L. Puente, D. Juárez, M. Bobadilla, C. F. Arias, and E. Calva, "The Salmonella ompC gene: structure and use as a carrier for heterologous sequences," Gene, vol. 156, no. 1, pp. 1-9, 1995.

[23] H. Nikaido and M. Vaara, "Molecular basis of bacterial outer membrane permeability," Microbiological Reviews, vol. 14, pp. 7391-7403, 1985. 

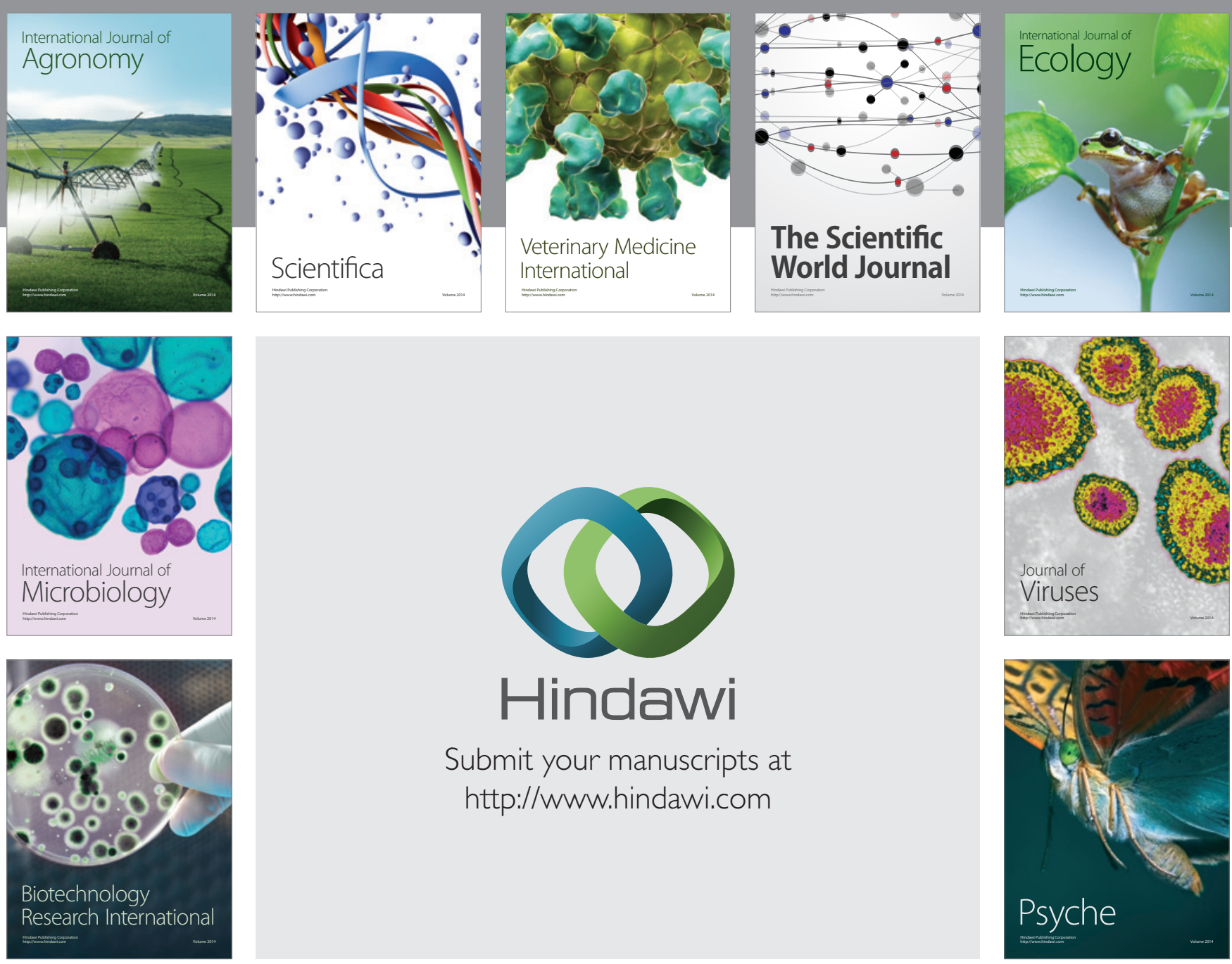

Submit your manuscripts at http://www.hindawi.com
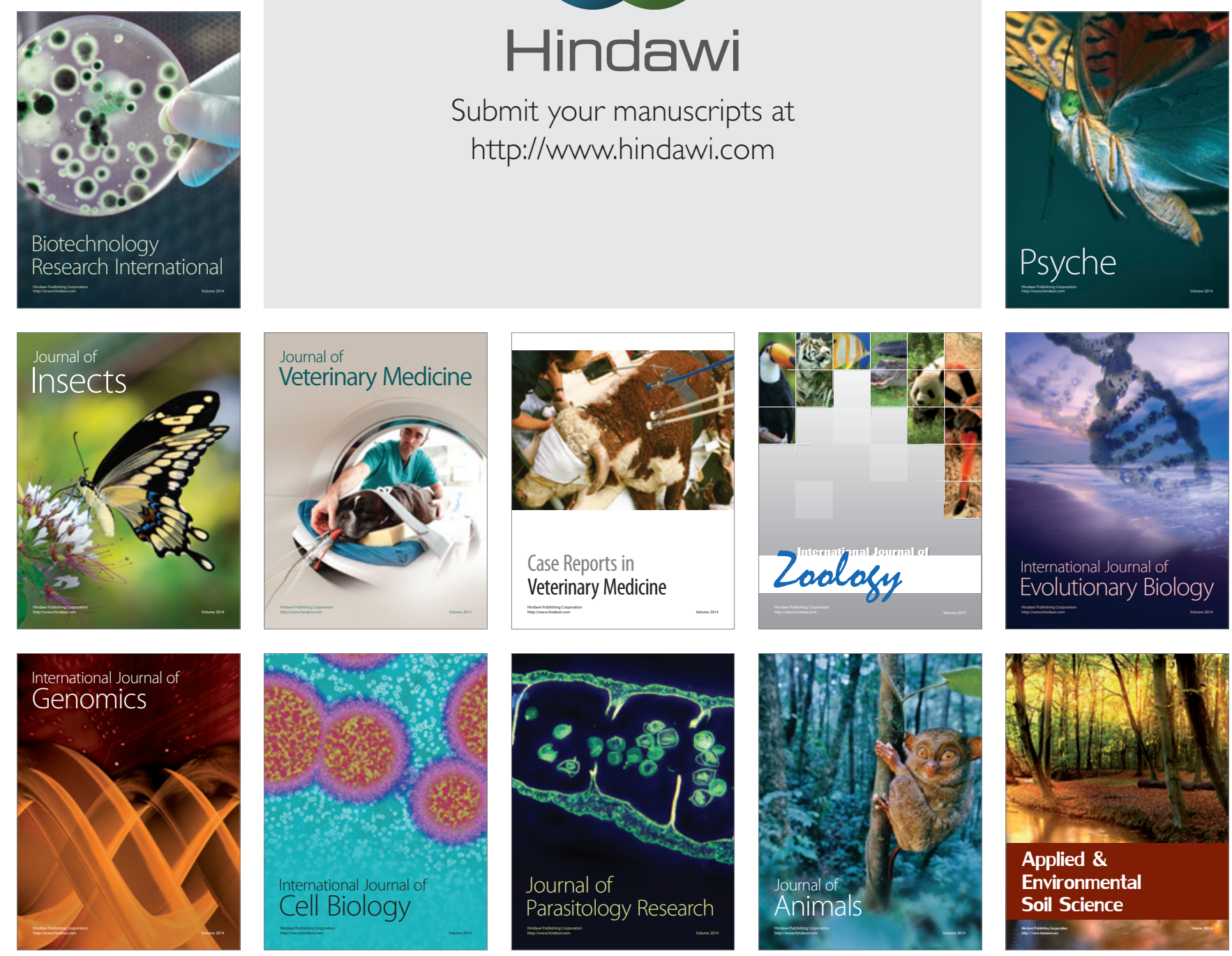